\title{
ARTICLE
}

\section{CPI motif interaction is necessary for capping protein function in cells}

Marc Edwards ${ }^{1}$, Patrick McConnell ${ }^{1}$, Dorothy A. Schafer ${ }^{2} \&$ John A. Cooper $^{1}$

Capping protein (CP) has critical roles in actin assembly in vivo and in vitro. CP binds with high affinity to the barbed end of actin filaments, blocking the addition and loss of actin subunits. Heretofore, models for actin assembly in cells generally assumed that $C P$ is constitutively active, diffusing freely to find and cap barbed ends. However, CP can be regulated by binding of the 'capping protein interaction' (CPI) motif, found in a diverse and otherwise unrelated set of proteins that decreases, but does not abolish, the actin-capping activity of CP and promotes uncapping in biochemical experiments. Here, we report that $C P$ localization and the ability of $\mathrm{CP}$ to function in cells requires interaction with a CPI-motif-containing protein. Our discovery shows that cells target and/or modulate the capping activity of CP via CPI motif interactions in order for CP to localize and function in cells.

\footnotetext{
${ }^{1}$ Department of Cell Biology and Physiology, Washington University School of Medicine, St Louis, Missouri 63110-1093, USA. ${ }^{2}$ Departments of Biology and Cell Biology, University of Virginia, Charlottesville, Virginia 22904-4328, USA. Correspondence and requests for materials should be addressed to J.A.C. (email: jacooper@wustl.edu).
} 
A ctin filament assembly is the basis for the formation of many subcellular structures and for performance of various cell functions ${ }^{1}$. Actin filaments grow and shrink via addition and loss of actin subunits at their ends. In cells, free barbed ends are critical determinants of the spatial and temporal regulation of actin assembly. Heterodimeric actin-capping protein (CP) binds to and functionally caps free barbed ends, blocking their growth and shrinkage ${ }^{2}$, with subnanomolar binding affinity and a half-time for dissociation of $\sim 30 \mathrm{~min}^{3-5}$. CP is found in essentially all eukaryotic cells; its importance in regulating actin assembly and actin-based motility is likewise universal.

A diverse set of otherwise unrelated proteins contain a $\sim 30$-residue motif, called CPI (capping protein interaction), that binds directly to $\mathrm{CP}$ and modulates its actin-capping activity $^{6}$. CPI motifs are found in CARMILs, CKIP-1, CapZIP, CD2AP, the CD2AP homologue CIN85 and the WASH (Wiskott-Aldrich syndrome protein and SCAR homologue) subunit Fam21. For CARMIL1, CD2AP and CKIP-1, the CPI motif is necessary for actin-based cellular functions, based on the failure of mutations in the CPI motif to rescue knockdown or overexpression actin phenotypes ${ }^{7-9}$.

The traditional view of CP function in cells has been that $\mathrm{CP}$ is active and freely diffusible in the cytoplasm ${ }^{10}$; CP stochastically encounters and caps free barbed ends to terminate filament elongation $^{2,11,12}$. This view is supported by synthetic studies with purified proteins in which capping barbed ends by diffusion is sufficient to promote actin-based motility ${ }^{13}$. In addition, mathematical models of actin-based motility in cells generally use the simplifying assumption that $\mathrm{CP}$ is a diffusible active capper, sufficient for activity on its own 14,15

On the other hand, models involving the regulation of $\mathrm{CP}$ in cells have been proposed. For example, uncapping of barbed ends capped by $\mathrm{CP}$ was proposed to generate free barbed ends during platelet activation, based on the observation that phosphatidylinositol 4,5-bisphosphate $\left(\mathrm{PIP}_{2}\right)$ releases gelsolin and $\mathrm{CP}$ from barbed ends ${ }^{16}$. In addition, free barbed ends induced by $\mathrm{Cdc} 42$ in neutrophils are protected from $\mathrm{CP}^{17}$, and formins and enabled/vasodilator-stimulated phosphoprotein (Ena-VASP) proteins protect barbed ends from $\mathrm{CP}^{6}$.

More recently, discoveries of CPI-motif proteins have raised the possibility that $\mathrm{CP}$ might be targeted to specific cellular locations ${ }^{18}$, and have its capping activity decreased or even reversed (uncapping) ${ }^{19}$, to achieve proper actin filament dynamics. In support of this view, depletion of CARMIL1 and $\mathrm{CD} 2 \mathrm{AP}$ was found to decrease localization of CP to the plasma membrane $(\mathrm{PM})^{7,8}$. In addition, the protein $\mathrm{V}-1 /$ myotrophin is known to inhibit CP in vitro ${ }^{2,20,21}$, and the CPI-motif protein CARMIL1 has been proposed to be part of a regulatory cycle promoting the release of CP from sequestration by V-1 (ref. 22).

Fundamental questions exist regarding the physiological function of the interaction of CPI-motif proteins with CP in cells. Do CPI-motif proteins decrease the actin-capping activity of $\mathrm{CP}$ at a given location or time, in order to limit or even reverse the capping of barbed ends? Alternatively, do CPI-motif proteins target active CP to sites where barbed ends need to be capped? Here, we tested the hypothesis that an interaction with a CPImotif protein is required for $\mathrm{CP}$ localization and function by examining the cellular activities of CP mutants that are unable to bind to the CPI motif, but that retain full ability to bind and cap barbed ends. We found that these CP mutants do not function in cells, producing actin phenotypes identical to loss of CP. The mutants failed to rescue RNA interference-induced knockdown of $\mathrm{CP}$, and the mutants had a dominant-negative effect in cells expressing endogenous CP.

\section{Results}

CP mutants defective in binding to CPI-motif proteins. To understand the role of $\mathrm{CP}$ regulation by $\mathrm{CPI}-$ motif proteins in cells, we created mutant forms of CP defective in binding the CPI motif, originally defined as LxHxTxxRPK(6X)P by Bruck et al. ${ }^{23}$. The CPI motif makes extensive and important close contacts with the CP $\beta$ subunit of the CP heterodimer ${ }^{21,24,25}$. For CP $\beta$, the residues Arg15 and Tyr79 make close contact with critical residues of the CPI motif in co-crystal structures ${ }^{24}$. Accordingly, we changed these residues to Ala. The single mutants are R15A and Y79A, and the double mutant is R15A/Y79A (plasmids in Table 1). We predicted that these CP mutants would be deficient in binding to all CPI-motif proteins.

We measured binding constants for the interaction of $\mathrm{CP}$ mutants with the capping protein-binding region (CBR) fragment of CARMIL1, which includes a CPI motif, using purified proteins and surface plasmon resonance (SPR). Representative SPR traces are shown in Fig. 1, and rate and binding constants based on complete data sets are listed in Table 2. SPR traces reveal that the binding affinity for each single mutant is less than that of wildtype CP by a factor of $>10$ and that the binding affinity for the double mutant is less by a factor of $>100$ (Fig. 1a,b). To calculate binding and rate constants, we fit complete time-course data for all the curves to a single-site model with 1:1 stoichiometry

\section{Table 1 | Plasmids used in this study.}

\begin{tabular}{lll} 
pBJ \# & Name & Description \\
\hline 1678 & Control shRNA & Control shRNA \\
2377 & CP shRNA & shRNA for targeting CP \\
2086 & PHR'8.2 $\Delta R$ & Lentiviral packaging plasmid \\
2087 & PCMV-VSV-G & Lentiviral packaging plasmid \\
1841 & GST-CARMIL1 CBR115aa & Bacterial expression of GST-CBR \\
2041 & His-CP $1 \beta 2$ & Bacterial expression of wild-type CP \\
2302 & His-CP $1 \beta 2$ R15A & Bacterial expression of R15A CP \\
2303 & His-CP $1 \beta 2$ Y79A & Bacterial expression of Y79A CP \\
2304 & His-CP $1 \beta 2$ R15A/Y7A & Bacterial expression of R15A/Y79A CP \\
2438 & GST-V-1 & Bacterial expression of GST-V-1 \\
2358 & YFP-CP $\alpha 1$ & Expression of YFP-CP 1 in mammalian cells \\
2359 & GFP-CP $\beta 2$ & Expression of GFP-CP $\beta 2$ in mammalian cells \\
2361 & GFP-CP $\beta 2$ R15A & Expression of GFP-CP 32 R15A in mammalian cells \\
2362 & GFP-CP $\beta 2$ Y79A & Expression of GFP-CP $\beta 2$ Y79A in mammalian cells \\
2363 & GFP-CP $\beta 2$ R15A/Y79A & Expression of GFP-CP $\beta 2$ R15A/Y79A in mammalian cells \\
\hline
\end{tabular}

CBR, capping protein-binding region; $C P$, capping protein; GFP, green fluorescent protein; GST, glutathione S-transferase; shRNA, short hairpin RNA. 

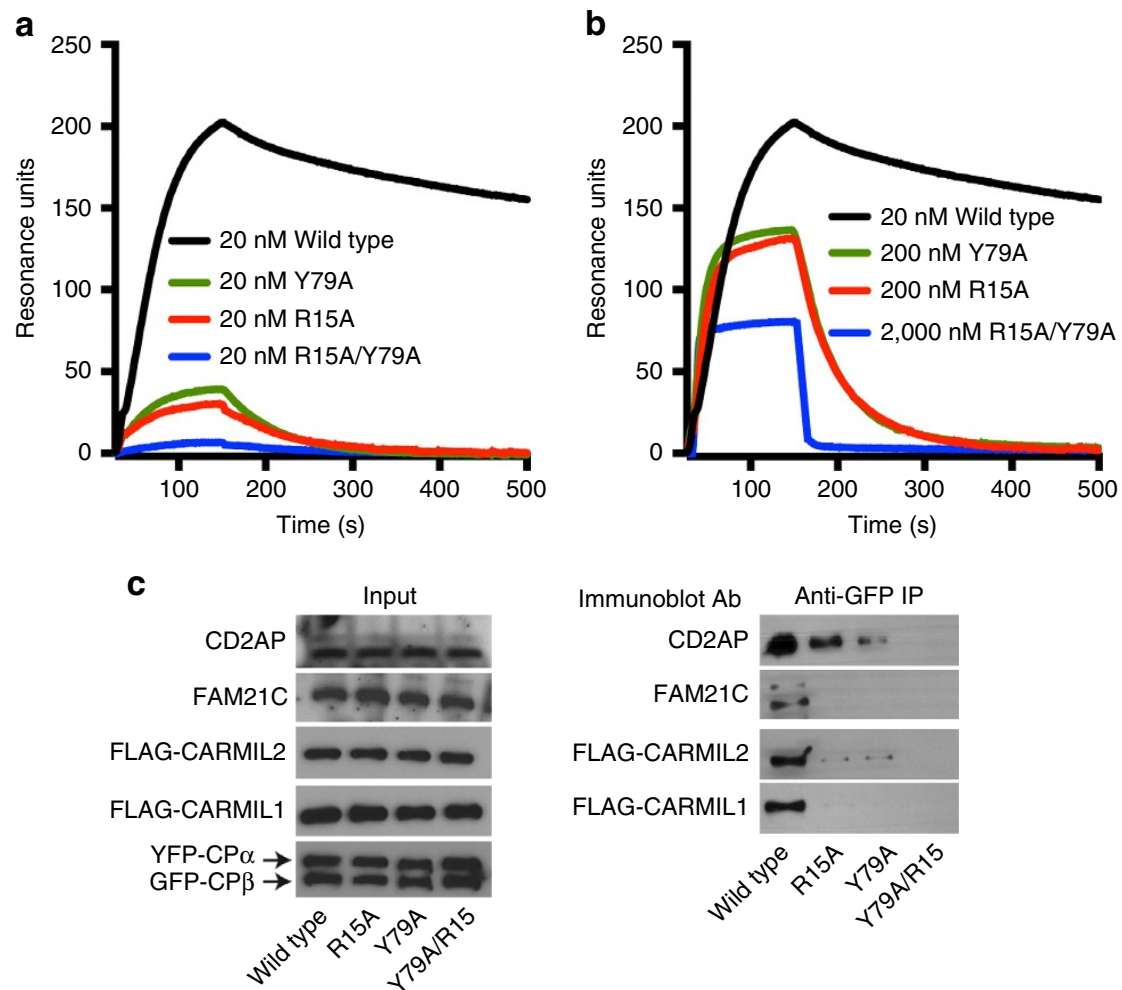

Figure 1 | CPI-motif binding-site mutations impair CPI-CP interaction. (a) Interaction of purified CP and CARMIL-CBR, assayed by SPR (surface plasmon resonance). The SPR chip contains GST fused to CBR of human CARMIL1. CP at $20 \mathrm{nM}$ was flowed over the chip. Black: wild-type CP, green: Y79A, red: R15A, blue: R15A/Y79A. One representative experiment, among four, is shown. (b) SPR traces as in $\mathbf{a}$, with concentrations of CP as follows: wild-type $20 \mathrm{nM}, \mathrm{R} 15 \mathrm{~A} 200 \mathrm{nM}, \mathrm{Y79A} 200 \mathrm{nM}, \mathrm{R} 15 \mathrm{~A} / \mathrm{Y} 79 \mathrm{~A}$ 2,000 nM. One representative experiment, among four, is shown. (c) Impaired association of CP mutants with CPI-motif proteins in cells. HT1080 cells expressed CP mutants tested in $\mathbf{a}$ and $\mathbf{b}$. Cells were co-transfected with YFP-CP $\alpha 1$ and either GFP-CP 32 , GFP-CP 32 R15A, GFP-CP 22 Y79A or GFP-CP 32 R15A/Y79A. CP was immunoprecipitated from whole-cell lysates with anti-GFP, and precipitates were probed with antibodies to endogenous CD2AP and Fam21C. For CARMIL1 and CARMIL2, endogenous levels were low, so cells were co-transfected with FLAG-tagged expression constructs, and IPs were probed with anti-FLAG.

Table 2 | Rate and binding constants for CP mutants.

\begin{tabular}{|c|c|c|c|c|}
\hline CP species & [Analyte] (nM) & $k_{+}\left(M^{-1} s^{-1}\right)\left(\times 10^{5}\right)$ & $k_{-}\left(s^{-1}\right)\left(\times 10^{-3}\right)$ & $K_{\mathrm{d}}(\mathrm{nM})$ \\
\hline Wild type & 20 & $10.4 \pm 1.5$ & $0.60 \pm 0.01$ & $0.60 \pm 0.11$ \\
\hline Y79A & 200 & $1.6 \pm 0.2$ & $19.8 \pm 0.3$ & $125 \pm 16$ \\
\hline
\end{tabular}

$\mathrm{CP}$, capping protein; ND, not determined; SPR, surface plasmon resonance.

Determined by SPR, based on fitting to curves as described in Methods. A term for mass transport did not improve the fit by a statistically significance amount. The dissociation rate constant $k_{-}$was determined first, from the dissociation phase. With $k_{-}$fixed, the association rate constant $k_{+}$was then determined from the association phase. $K_{d}$ is the quotient of $k_{-} / k_{+}$. ND-not determined because

of weak signal and high error due to low binding.

(Table 2). The kinetic modelling yielded independent values for association and dissociation rate constants, $k_{+}$and $k_{-}$, which were used to calculate the binding constant, $K_{\mathrm{d}}$. The results for wild-type CP were similar to those from previous studies, with a $K_{\mathrm{d}}<1 \mathrm{nM}^{5}$. The $K_{\mathrm{d}}$ for each of the single mutants was $\sim 140 \mathrm{nM}$, with $\sim 10$-fold decreases in $k_{+}$and $\sim 20$-fold increases in $k_{-}$. For the double mutant, the $k_{-}$was increased further, by a factor of 5 , and $k_{+}$could not be determined because the extent of binding was too low. Thus, we estimate a lower limit for the $K_{\mathrm{d}}$ of $>100 \mu \mathrm{M}$ for the double mutant.

We tested the ability of four different CPI-motif proteinsCARMIL1, CARMIL2, CD2AP and FAM21C - to bind to the $\mathrm{CP}$ mutants in cells by immunoprecipitation (Fig. 1c). Interactions of all four proteins with the R15A/Y79A mutant were severely decreased, to near zero, based on the amounts of co-precipitated protein. For the single mutants, levels of coprecipitated proteins were also decreased, to very low or undetectable levels (Fig. 1c).

Biochemical properties of CP mutants. The rationale for our approach required that the CP mutants bind and cap actin filaments normally, which we expected based on the location of the mutated residues in the structure ${ }^{24}$. Indeed, we tested the actin-capping activity of the $\mathrm{CP}$ mutants over a range of concentrations and found them to be essentially identical to that of wild-type CP (Fig. 2a; Supplementary Fig. 1A-D).

We expected that decreased physical binding of the $\mathrm{CP}$ mutants to CPI motifs, as detected by SPR and 

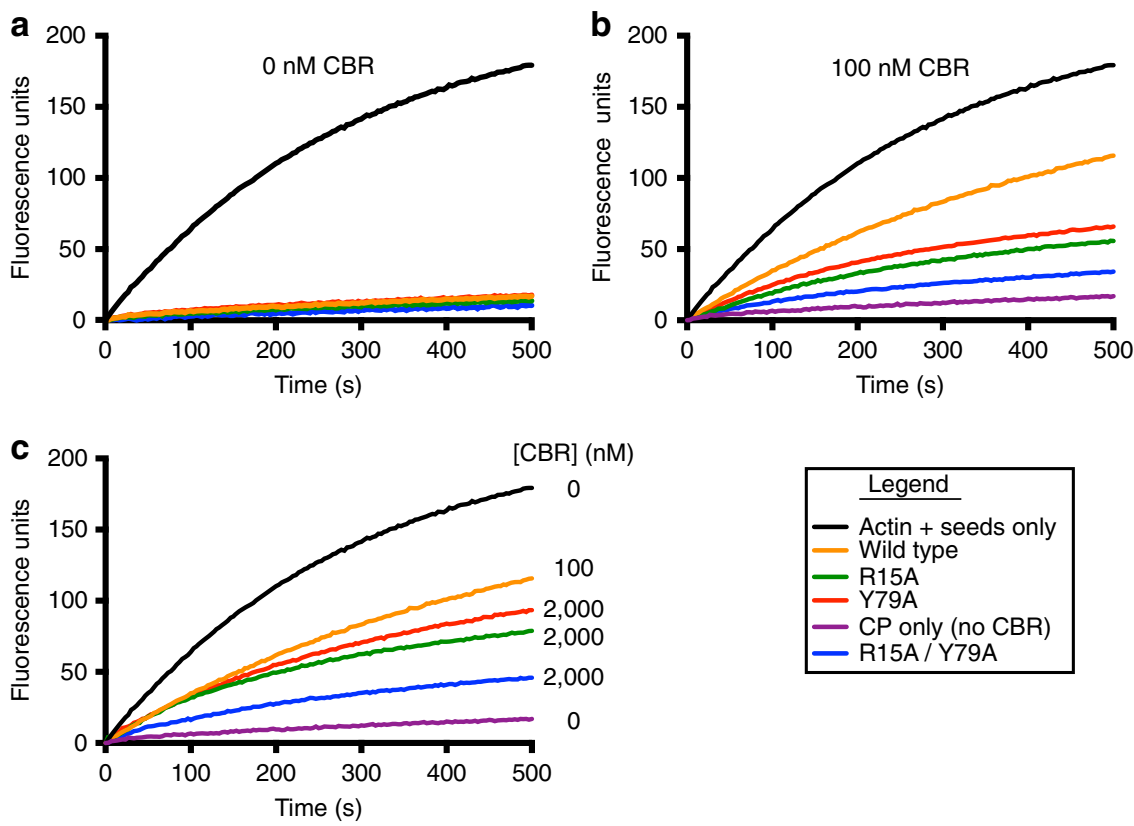

Figure 2 | CP mutants cap actin normally but resist inhibition by the CPI motif. (a) Actin-capping activity is not affected by the CP mutations. Actin polymerization from barbed ends, revealed by pyrene-actin fluorescence versus time. CP $(10 \mathrm{nM})$, wild-type and mutants, were added. Curve colours as follows: control without CP (black), wild-type CP (orange), CP R15A mutant (green), CP Y79A mutant (red) and CP R15A/Y79A mutant (blue). (b) Inhibition of CP by the CBR fragment of CARMIL1. Experiment as in $\mathbf{a}$, with addition of $100 \mathrm{nM} \mathrm{CBR}$ at $t=0$. Colours as in $\mathbf{a}$, with the addition of control with wild-type CP and no CBR (purple). (c) Similar to b, with higher concentration (2,000 nM) of CBR for CP R15A, Y79A and R15A/Y79A. The black, orange and purple curves are the same in $\mathbf{b}$ and $\mathbf{c}$. For all panels, one experiment is shown, representative of three.

co-immunoprecipitation, would be accompanied by decreased functional ability of CPI-motif proteins to inhibit the actin-capping activity of the CP mutants. We measured inhibition of capping activity for each CP mutant using CBR, a CPImotif-containing fragment of CARMIL1 (Fig. 2b,c). As expected, the effect of CBR on CP mutants was much less than its effect on wild-type CP. The single-CP mutants were only partially inhibited by $\mathrm{CBR}$, and the double-CP mutant showed only minimal inhibition, consistent with the physical binding assays. In one experimental design, $\mathrm{CP}$ and $\mathrm{CBR}$ concentrations were kept constant (Fig. 2b); in another design, CBR concentration was varied (Fig. 2c). Overall and most important, the double-CP mutant exhibited nearly undetectable interaction with CPI-motif proteins, in physical and functional assays.

We characterized the R15A/Y79A mutant further by testing interaction with the other known inhibitors of $\mathrm{CP}-\mathrm{PIP}_{2}$ and $\mathrm{V}-1$. V-1 competitively inhibits actin capping by binding to $\mathrm{CP}$ at a site that overlaps with the actin-binding site ${ }^{26} . \mathrm{PIP}_{2}$ also binds to and inhibits $\mathrm{CP}^{27,28}$. In actin-capping assays with purified proteins, addition of $\mathrm{V}-1$ and $\mathrm{PIP}_{2}$ had similar inhibitory effects on wild-type CP and the R15A/Y79A mutant (Supplementary Fig. 2; Supplementary Fig. 3).

Localization of CP mutants in cells. We tested the hypothesis that interaction with a CPI-motif protein is required for the localization of $\mathrm{CP}$, as opposed to the simple alternative that $\mathrm{CP}$ freely diffuses to encounter and bind free barbed ends. The CPI-motif proteins CD2AP and CARMIL1 have been found to co-localize with $\mathrm{CP}$ in the actin-rich cell cortex ${ }^{7,8,29}$. In those studies, mutation of the CPI motif led to loss of CP localization at the cortex, but the mutations also led to loss of F-actin accumulation, leaving open the possibility that $\mathrm{CP}$ binding and accumulation depended on F-actin. In other studies, CP localized to macropinosomes and vesicular compartments in association with the CPI-motif protein Fam21, a component of the WASH complex $^{30}$. Loss of Fam 21 led to loss of CP and WASH co-localization at vesicle membranes; instead, CP was associated with abnormal F-actin streams emanating from vesicles, while WASH remained at the membrane ${ }^{31}$. These findings support the hypothesis that interaction with a CPI motif is required to localize $\mathrm{CP}$ at cellular membranes, rather than its passive diffusion and binding to actin filament barbed ends.

To test this hypothesis, we localized green fluorescent protein (GFP)-tagged versions of wild-type CP 32 (ref. 30) and double-mutant CP (R15A/Y79A $\beta 2$ ) (Fig. 3). GFP-CP fusions were expressed in HT1080 cells at very low levels, so that neither wild-type nor mutant produced any observable effect on the morphology or actin cytoskeleton of the cells. Wild-type CP was enriched at the leading edge of cells and concentrated in puncta associated with macropinosomes and vesicular structures (Fig. 3, arrows). In contrast, the R15A/Y79A mutant remained diffuse and failed to localize to the leading edge of cells and to macropinosomes, in all of the 37 cells analysed (Fig. 3; Supplementary Fig. 4)

We quantified PM localization by calculating the PM index ${ }^{32}$, which accounts for volume effects by normalizing the membraneassociated signal to that of a cytoplasmic marker. The PM index of GFP was near zero (0.06), as expected for a freely diffusing protein. The value for wild-type CP was 1.28 , and the value for the R15A/Y79A mutant was 0.12 (Supplementary Fig. 4). Because the R15A/Y79A mutant binds barbed ends normally, we conclude that localization of $\mathrm{CP}$ in cells requires binding interaction with a CPI-motif protein, not to barbed ends of actin filaments.

Function of CP mutants in cells. To assess the physiological importance of the CP-CPI interaction, we asked whether and how CP mutants function in cells, focusing on actin assembly and dynamics. We reasoned that if CPI motifs target or recruit CP to 

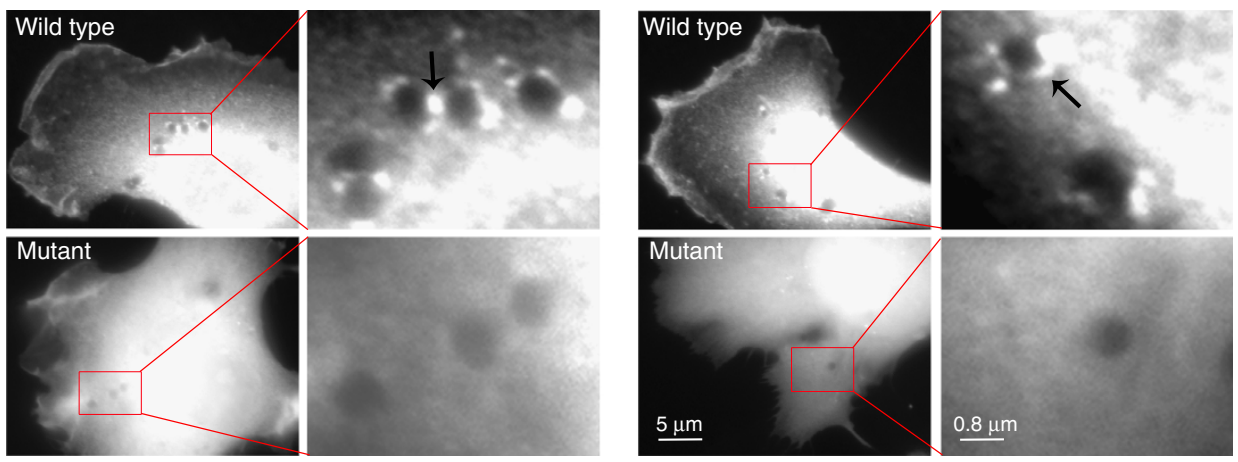

Figure 3 | CP localization depends on the ability to bind CPI-motif proteins. GFP-tagged fusions of wild-type CP 32 or the R15A/Y79A mutant were expressed in cells at low levels. Cells were fixed and immunostained with anti-GFP. Representative images are shown; $n=27$ cells. Red rectangles indicate the region of the cell magnified in the adjacent inset. Arrows indicate puncta of CP. The expression levels in this experiment were far lower than the levels used to induce changes in cell shape and actin distribution, described later.

certain locations and if recruitment is necessary for function, then the phenotype of cells expressing CP mutants should phenocopy the loss of CP. Alternatively, if the role of CPI motifs is to inhibit $\mathrm{CP}$ and prevent capping or promote uncapping, then $\mathrm{CP}$ mutants unable to bind CPI motifs should cap constitutively, and their cellular phenotype should resemble the effects of increased levels of $\mathrm{CP}$ and actin capping.

To test these hypotheses, we expressed the CP $\beta$-subunit mutants in HT1080 cells depleted of endogenous CP by targeting the $\beta$-subunit with short hairpin RNA (shRNA) (Fig. 4). CP depletion led to a loss of lamellipodia and an increase in filopodia, consistent with previous results in mouse B16 cells $^{33}$ and Dictyostelium $^{34}$. Expression of shRNA-resistant wild-type CP restored the actin phenotype to that of control cells; lamellipodia appeared and filopodia were lost. In contrast, expression of shRNA-resistant R15A/Y79A mutant did not provide rescue; cells lost lamellipodia and gained filopodia, similar to CP-depleted cells. Representative images are shown in Fig. 4a, and quantitative analysis of filopodia number, scored by a blinded observer, is plotted in Fig. 4b. In addition, CP depletion caused an increase in the total level of F-actin per cell, based on fluorescent phalloidin (Fig. 4c), consistent with previous reports ${ }^{34,35}$. This phenotype was also rescued by expression of wild-type $\mathrm{CP}$, but not the R15A/Y79A mutant (Fig. 4c). The single mutants, R15A or Y79A, produced results similar to wild type (not shown). The levels of expressed double- and single-mutant forms of CP were the same as or slightly greater than the level of endogenous wild-type CP by immunoblot (Supplementary Fig. 5).

To test the function of the CP mutants further, we expressed them in cells where endogenous CP was not depleted (Fig. 5a,b). Mutant or wild-type forms of CP $\beta$ were transiently expressed, along with the wild-type $\mathrm{CP} \alpha$ subunit. Expression of wild-type $\mathrm{CP}$ or the two CP mutants with single amino-acid changes, R15A or Y79A, had small effects on cell morphology (Fig. 5a) and on the quantitative scores of lamellipodia and filopodia (Fig. 5b). In contrast, expression of the R15A/Y79A mutant caused large effects, with decreased lamellipodia and increased filopodia, closely resembling the effects of depleting $\mathrm{CP}$ (Fig. 5b). Together the results show that a mutant form of $\mathrm{CP}$ defective in binding to CPImotif proteins has a dominant-negative effect on cells, which argues that the mutant $\beta$-subunits fold and interact with the $\alpha$-subunit in a normal manner. On the basis of these results, we conclude that $\mathrm{CP}$ is required to bind to a CPI-motif protein to function in cells.

Increasing cellular (CP) decreases cellular F-actin levels. To test the model in which CPI-motif proteins only inhibit CP, without a

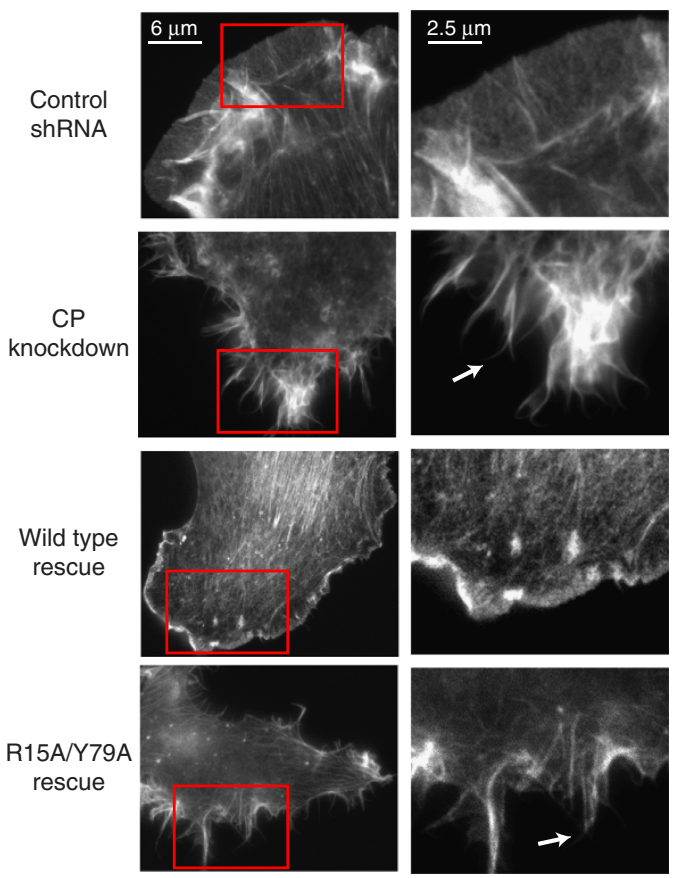

b
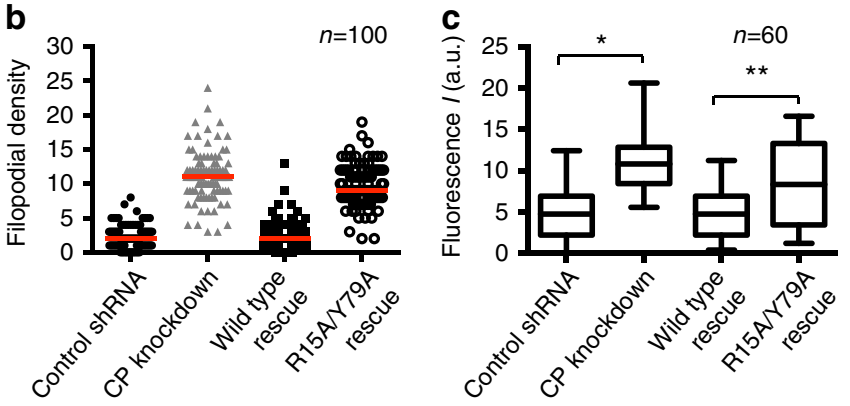

Figure 4 | CP mutants fail to rescue CP-depletion phenotypes. (a) Images of CP-depleted cells expressing wild-type CP or R15A/Y79A mutant, stained with fluorescent phalloidin. Arrows indicate filopodia. Red boxes in left panels are magnified on the right. (b) Quantification of filopodia density. The $y$ axis is the number of filopodia per $10 \mu \mathrm{m}$ of cell perimeter; $n=100$ cells. (c) Quantification of whole-cell phalloidin staining density from (a). The difference between control shRNA and CP knockdown is significant $\left({ }^{\star} P<0.01\right)$; the difference between mutant and wild-type rescue is also significant $\left({ }^{\star \star} P<0.02\right)$. 

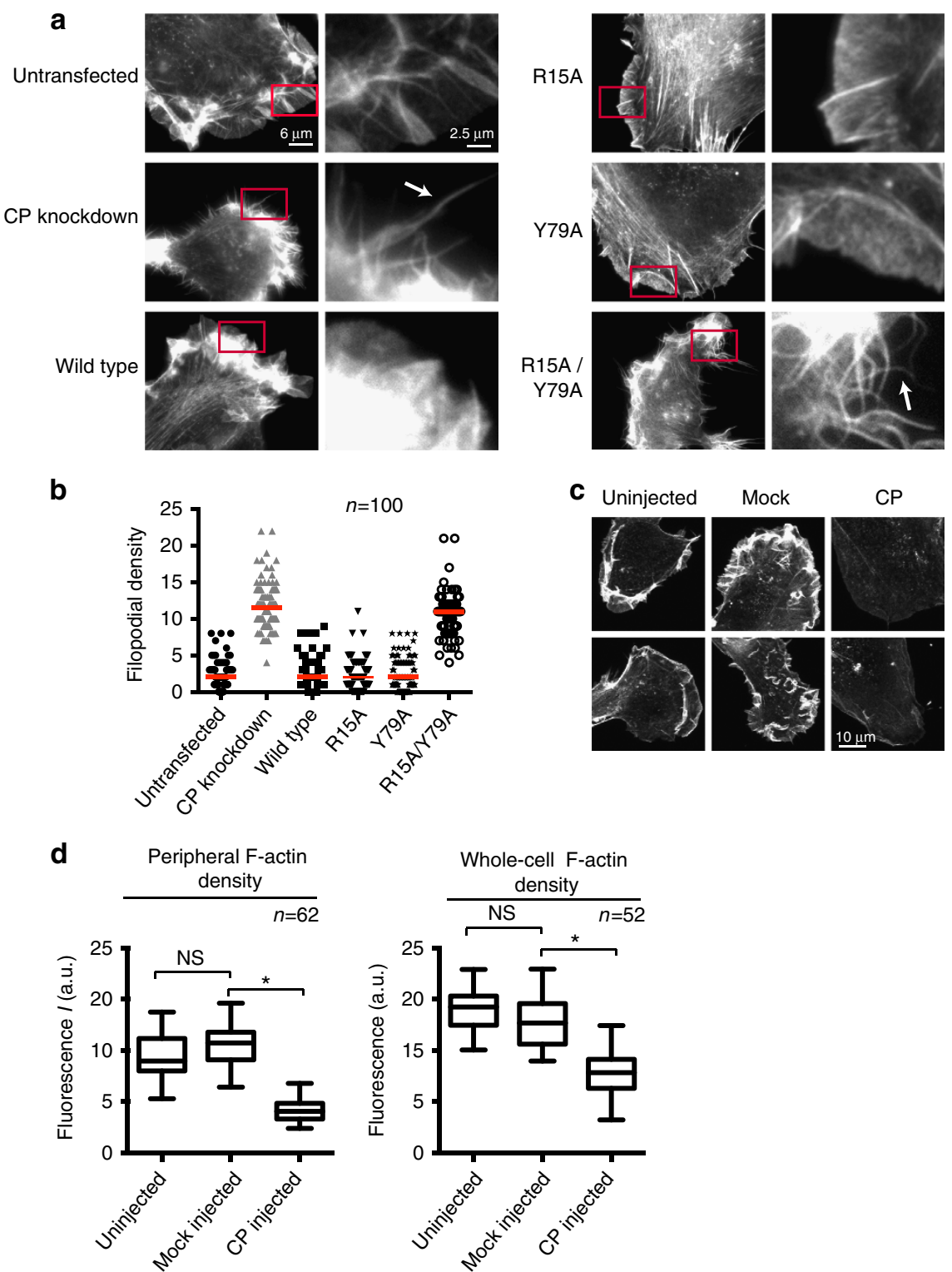

C
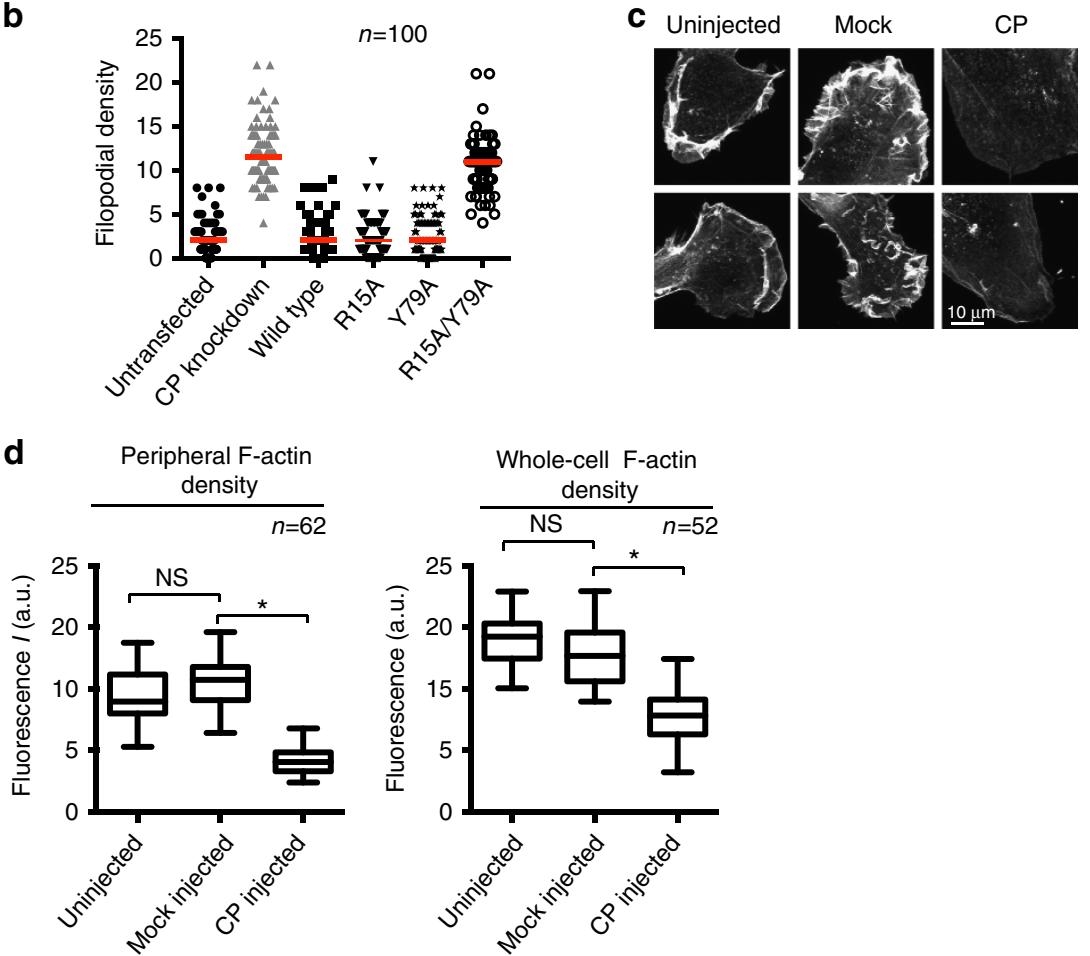

Figure 5 | Overexpression of CP R15A/Y79A mutant mimics depletion of CP. (a) Cells were transfected with the indicated constructs and stained with fluorescent phalloidin. Arrows indicate filopodial protrusions. Red boxes in left panels are magnified to the right. (b) Quantification of filopodia density. The $y$ axis is the number of filopodia per $10 \mu \mathrm{m}$ of cell perimeter; $n=100$ cells. (c) Increased cellular CP did not affect F-actin organization. Cells were microinjected with a mixture of purified wild-type $\mathrm{CP}(78.5 \mu \mathrm{M})$ and a fixable rhodamine-dextran marker. Cells were stained with fluorescent phalloidin. Mock-injected cells received only the rhodamine-dextran marker. Maximum-intensity projections of confocal images are shown. (d) Quantification of whole-cell and cortical phalloidin staining densities from $\mathbf{c}$. The difference between CP-injected and mock-injected cells is statistically significant $\left({ }^{\star} P<0.01\right)$, whereas the difference between mock-injected and uninjected cells is not. NS, not significant.

spatial targeting of capping activity, we sought additional evidence that the expressed $\mathrm{CP}$ mutant proteins did not provide a gain of $\mathrm{CP}$ function in cells, and thereby alter cellular actin structures. In previous studies with Dictyostelium, the effects of overexpressing $\mathrm{CP}$ on F-actin structures was clearly distinct from that of depleting $\mathrm{CP}^{34}$. To increase the level of CP in HT1080 cells, we microinjected purified wild-type $\mathrm{CP}$, at the highest concentration possible, into the cytoplasm of cells with a microneedle (Fig. 5c). Cells, which typically have $1-2 \mu \mathrm{M}$ cytoplasmic $\mathrm{CP}^{17,36}$, were injected with purified $\mathrm{CP}$, producing a four- to eightfold increase in cellular $\mathrm{CP}$ concentration.

$\mathrm{CP}$-injected cells displayed a distinct lack of ruffling at the periphery when compared with uninjected or mock-injected cells (Fig. 5c). The number of filopodia was not increased, in striking contrast to the loss of CP. In addition, CP-injected cells exhibited decreased F-actin density, both in the lamellipodial region at the cell edge, and globally, as quantified from the intensity of fluorescent phalloidin staining (Fig. 5d). Thus, the effects of overexpressing and depleting CP in HT1080 cells differed, as observed in Dictyostelium ${ }^{34}$. These results demonstrate that the effects of the $\mathrm{CP}$ mutant proteins on cellular actin structures do not result solely from elevated actin-capping activity. We conclude that the CPI motif acts to selectively target $\mathrm{CP}$ to specific actin networks, where it promotes uncapping of capped actin filaments or provides a decreased level of capping activity tuned to the dynamics of actin assembly. 
a

Untreated

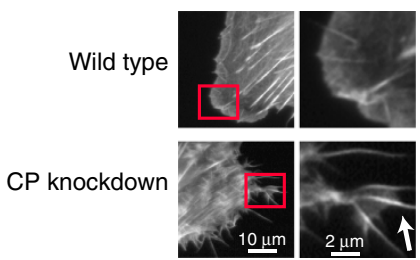

b
DMSO (vehicle)

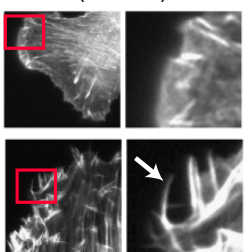

CK666

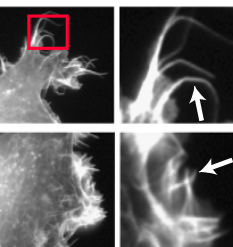

Washout

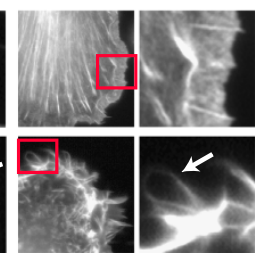

$n=50$

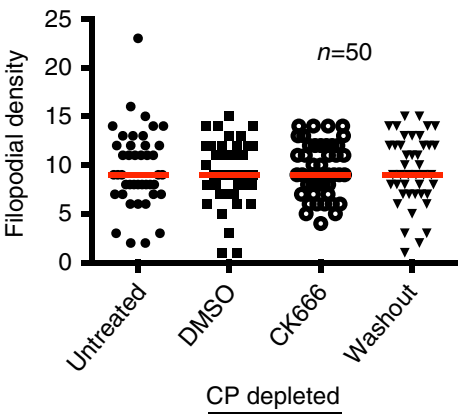

Figure 6 | Effects of inhibition of Arp2/3 complex resemble loss of CP function. a) Cells were treated with the Arp2/3 complex inhibitor CK-666 in dimethyl sulfoxide (DMSO) for $3 \mathrm{~h}$, then stained with fluorescent phalloidin. Negative controls included no treatment and vehicle (DMSO). In the washout sample, CK-666 was removed by washing with growth media, five times over $30 \mathrm{~min}$. As a control, the inactive compound CK-689 produced no effect. Upper row: control cells. Lower row: cells treated with lentivirus-expressing CP shRNA targeting the CP $\beta$-subunit. Arrows indicate filopodia. Representative images from 20 cells are shown. (b) Quantification of normal lamellipodia (black) and increased filopodia (grey). The $y$ axis is the number of cells; $n=50$.

Loss of CP function resembles loss of Arp2/3 function. In the dendritic nucleation model for actin assembly induced by Arp $2 / 3$ complex, CP has an essential role, capping barbed ends after they have grown for a short period of time. This view is supported by the observation that $\mathrm{CP}$ depletion leads to loss of the branching actin filament networks in lamellipodia ${ }^{33}$, as well as the finding that a barbed-end capper, such as $\mathrm{CP}$, is a necessary component for synthetic reconstitution of Arp2/3-mediated actin-based motility ${ }^{37,38}$. Thus, we asked whether loss of function of CP in HT1080 cells resembles loss of function of the Arp2/3 complex by treating cells with the Arp2/3 inhibitor CK-666 (ref. 39). The effects on lamellipodial F-actin were similar to those observed when CP was depleted (Fig. 6). Furthermore, as a test for functional overlap between $\mathrm{CP}$ and the Arp2/3 complex, we treated CP-depleted cells with CK-666. No additional effects on F-actin organization were observed, indicating that $\mathrm{CP}$ and the Arp2/3 complex are both necessary for lamellipodia formation, as predicted by the dendritic nucleation model ${ }^{12}$.

\section{Discussion}

We discovered that $\mathrm{CP}$ requires an interaction with a CPI-motif protein for its function in cells. This conclusion contradicts the idea that CP randomly diffuses about the cytosol, stochastically colliding with free barbed ends and capping them ${ }^{2}$. This view of $\mathrm{CP}$ function has been widely held and applied since its discovery and initial characterization 35 years ago ${ }^{10}$; the dendritic nucleation model for Arp2/3-based actin assembly incorporates this view implicitly ${ }^{12}$. Moreover, this view is an explicit assumption of many physical and mathematical models for actin assembly and actin-based motility ${ }^{14,15,40}$.

Our conclusion is based on the observation that point mutations of $\mathrm{CP}$, which prevent its binding to a CPI-motif protein, but which retain normal filament capping activity, mimic the loss of CP function in cells. The CP mutations caused loss of binding to CPI-motif proteins in biochemical assays with purified proteins, and they abrogated interactions of CPI-motif proteins with $\mathrm{CP}$ in cells, based on pulldowns from whole-cell lysates.
Finally, we found that the CPI-binding mutant CPs localized diffusely in the cytoplasm and did not accumulate at sites of dynamic actin assembly as wild-type CP did.

Together our findings suggest new models for regulation of actin assembly in cells by CP. We envision two important functions, not exclusive of one another, that result from the essential interaction of CP with a CPI-motif protein. First, a CPImotif protein may target $\mathrm{CP}$, and therefore actin-capping activity, to specific locations in the cell, such as membranes (Fig. 7). Second, the CPI motif/CP interaction may tune the barbed-end capping activity of $\mathrm{CP}$ to an optimal range, appropriate for the temporal regulation of actin dynamics in cells, by increasing the rate at which CP dissociates from capped barbed ends. For actin filaments capped by CP, CPI-motif proteins may uncap the barbed ends.

CPI motifs are found in a diverse set of otherwise unrelated proteins $^{6}$. Most CPI-motif proteins bind to PMs and intracellular membranes via distinct domains, suggesting that they serve as platforms for spatiotemporal regulation of actin assembly dynamics. Previous studies of two CPI-motif proteins, CD2AP and CARMIL1, demonstrate their ability to both target CP and tune its actin-capping activity ${ }^{7,8}$. CPI-motif proteins vary in their affinity for $\mathrm{CP}$ and in the extent to which they modulate capping activity. One set of CPI-motif proteins, the CARMIL family, have a second motif that also interacts with CP, termed the CARMILspecific interaction motif ${ }^{24}$. This second motif appears to enhance the binding affinity and regulatory effects of $\mathrm{CP}$. The range of capping activities exhibited by various CPI-CP complexes, together with independent regulation of these interactions by signalling proteins, suggests an underappreciated mechanism for local regulation of actin polymerization induced by the Arp2/3 complex and formins at membranes.

Previous studies provided evidence for the existence of $\mathrm{CP}$ inhibitors in cells. The apparent affinity of CP for barbed ends in cells is $\sim 100$-fold weaker than the calculated subnanomolar affinity for actin filaments observed in vitro ${ }^{34}$. The time for dissociation of CP from barbed ends of actin filaments in vitro is $\sim 500$-fold longer than the dissociation rates in cells observed by 


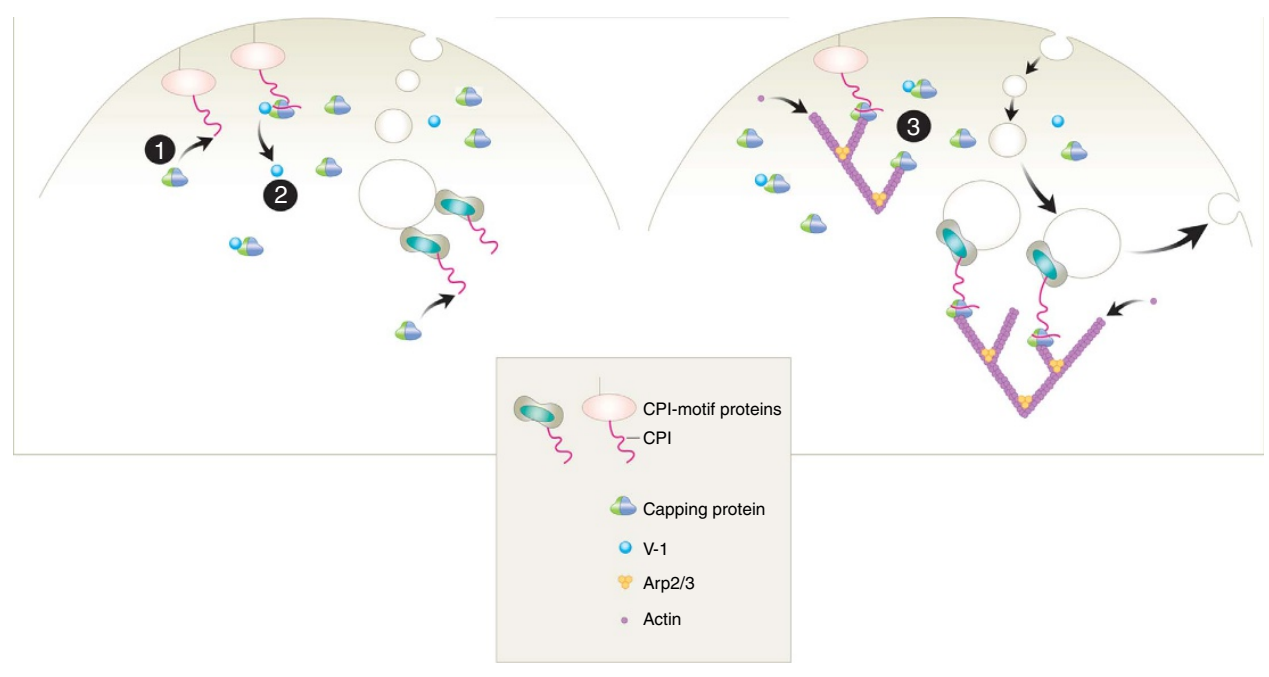

Figure 7 | CP localization and function requires interaction with CPI-motif proteins. CPI-motif proteins facilitate the recruitment of free cytosolic CP to biological membranes via the CPI motif (1). The CPI-CP interaction accelerates the dissociation of V-1 bound to CP (2). CPI-CP complex caps the barbed end of growing actin filaments near the membrane and promotes dendritic actin network growth and dynamics (3).

single-molecule analysis ${ }^{4,41}$. The $\sim 50$-fold decreased affinity of the $\mathrm{CP}-\mathrm{CPI}$ capping complex for the barbed end in vitro suggested one possible explanation for this discrepancy ${ }^{18}$, and the existence of a ternary CP-CPI-actin complex, implied by this model, was demonstrated clearly in vitro ${ }^{22,42}$. Indeed, our results here argue that such a complex is physiologically relevant in cells (Fig. 7).

The protein $\mathrm{V}-1$, also known as myotrophin, binds to $\mathrm{CP}$ at its actin-binding site, serving as a competitive inhibitor of capping in vitro. If $\mathrm{V}-1$ also functions in this manner in cells, then CPImotif proteins may form part of a regulatory cycle for $\mathrm{CP}$ that counteracts and relieves inhibition by $\mathrm{V}-1$ (ref. 22). In such a model, proposed by Hammer et al., the allosteric effects of a CPImotif protein, such as CARMIL1, would release CP from inhibition by $\mathrm{V}-1$, creating a CP-CPI complex with physiological capping activity. Our results here are consistent in principle with such a model. The role of $\mathrm{V}-1$ in cells with respect to actin remains relatively uncertain, especially in light of the known interaction of $\mathrm{V}-1$ with NF-kB signalling pathways ${ }^{43}$.

Our results, combined with previous studies on regulation of $\mathrm{CP}$ by a variety of proteins and lipids, indicate that we have much to learn about the dynamics of actin assembly in cells. The physiological significance of individual regulatory interactions and mechanisms for combining the actions of individual regulators are important open questions.

\section{Methods}

Antibodies and reagents. Reagents and materials were from Fisher Scientific (Pittsburgh, PA) or Sigma-Aldrich (St Louis, MO), unless stated otherwise. Antibody to CP was mouse monoclonal antibody clone $2 \mathrm{~A} 3$ for immunoblots 4 . Other antibodies and sources were as follows: Fam21C (rabbit pAb) from Millipore (Billerica, MA), anti-CD2AP (rabbit pAb) was a kind gift from Dr Andrey Shaw of Washington University, goat anti-Dap12 from Santa Cruz (Dallas, TX), anti-GFP (rabbit pAb) and rabbit anti-GST antibody from Abcam (Cambridge, MA) and anti-FLAG (mouse monoclonal antibody M2) from Sigma-Aldrich. Dynabeads, Protein G, HRP- and Alexa-conjugated secondary antibodies and Alexa 488- and Alexa 568-conjugated phalloidin were from Life Technologies (Carlsbad, CA). Arp2/3 complex inhibitors CK-666 and CK-869 (ref. 39), along with the control compound CK-689, were purchased from Sigma-Aldrich. pERFPC-1 and pEGFPC-1 were obtained from Clontech (Mountain View, CA). PIP $_{2}$ was obtained from Avanti Polar Lipids (Alabaster, AL).

Protein expression and purification. Plasmids used in this study are listed in Table 1. CP mutants were generated by site-directed mutagenesis (QuikChange, Stratagene Agilent, La Jolla, CA) of the His-tagged expression plasmid. Arginine 15 and tyrosine 79 of mouse CP $\beta 2$ (GenBank FJ692320.1) were both changed to alanine to produce two single mutants R15A and Y79A and one double mutant R15A/Y79A

His-tagged CP proteins were expressed in Escherichia coli BL21 (DE3, pRIL). They were purified as described ${ }^{24}$, with gel filtration chromatography on Sephacryl $\mathrm{S}-200 \mathrm{HR}$ (GE Healthcare) in $20 \mathrm{mM}$ Tris- $\mathrm{HCl} \mathrm{pH} \mathrm{7.4,50} \mathrm{mM} \mathrm{KCl,} 0.5 \mathrm{mM}$ Tris (2-carboxyethyl)phosphine (TCEP) and $1 \mathrm{mM} \mathrm{NaN}_{3}$. Proteins were snap-frozen in liquid nitrogen and stored at $-70{ }^{\circ} \mathrm{C}$.

Glutathione $S$-transferase (GST)-tagged CBR fragment of human

CARMIL1a (GenBank FJ009082), residues Glu964 to Ser1078 was expressed in E. coli BL21 (DE3, pRIL), affinity-purified on Glutathione Sepharose Fast-Flow (GE Healthcare), followed by chromatography on DEAE Sepharose Fast-Flow (GE Healthcare). Purified GST-CBR was exchanged into $20 \mathrm{mM}$ Tris-HCl pH 7.4, $50 \mathrm{mM} \mathrm{KCl}, 0.5 \mathrm{mM}$ dithiothreitol, $1 \mathrm{mM} \mathrm{NaN}_{3}$, snap-frozen in liquid nitrogen and stored at $-70{ }^{\circ} \mathrm{C}$.

GST-tagged V-1 was expressed in E. coli BL21 Star (DE3) (Life Technologies), affinity-purified on Glutathione Sepharose Fast-Flow (GE Healthcare), chromatographed on Sephacryl S-200 HR (GE Healthcare) in $20 \mathrm{mM}$ Tris- $\mathrm{HCl} \mathrm{pH}$ 7.4, $50 \mathrm{mM} \mathrm{KCl}, 1 \mathrm{mM}$ TCEP, $1 \mathrm{mM} \mathrm{NaN}_{3}$, snap-frozen in liquid nitrogen and stored at $-70^{\circ} \mathrm{C}$.

Actin polymerization assays and SPR. Pyrene-actin polymerization assays were performed as described ${ }^{40}$. Elongation rates were measured using time-based scans on a steady-state fluorometer (QuantaMaster, PTI, Edison, NJ) with excitation at $368 \mathrm{~nm}$ and emission at $386 \mathrm{~nm}$. Actin monomer concentration was $1.5 \mu \mathrm{M}$ with $5 \%$ pyrene labelling. The indicated concentrations of CP, GST-CBR, GST-V-1 and $\mathrm{PIP}_{2}$ were added at the start of the experiments. Pyrene-actin filament seeds were prepared as described ${ }^{44}$. Spectrin-actin seeds were prepared from a low-ionicstrength extract of bovine red blood cell ghosts as described ${ }^{45}$. Extraction of the ghost pellet was performed at $37^{\circ} \mathrm{C}$ for $40 \mathrm{~min}$ followed by centrifugation at $110,000 \mathrm{~g}$. The supernatant was collected and an equal volume of ethylene glycol was added for storage at $-20^{\circ} \mathrm{C}$.

Binding kinetics were measured by SPR using a Reichert SR7000 Single Channel Surface Plasmon Resonance System at $25^{\circ} \mathrm{C}$. Rabbit anti-GST antibody was immobilized onto a carboxymethyldextran chip (Reichert Technologies, gold sensor slide, 500,000 Da) using carbodiimide coupling. Goat anti-Dap12 Ab was used as a negative control. GST-CBR was injected onto the chip containing the immobilized antibodies. Next, wild-type or mutant $\mathrm{CP}$ was injected at $25 \mu \mathrm{min}^{-1}$. The buffer for GST-CBR and CP was $20 \mathrm{mM}$ Tris- $\mathrm{HCl} \mathrm{pH} 7.4,150 \mathrm{mM} \mathrm{NaCl}$, $5 \mathrm{mM}$ EDTA, $0.5 \mathrm{mM}$ TCEP, $0.005 \%$ Tween-20 and $1 \mathrm{mM} \mathrm{NaN}$. Chip regeneration was performed with $3.5 \mathrm{M} \mathrm{MgCl}_{2}, 20 \mathrm{mM} \mathrm{MES}$ pH 6.5.

$\mathrm{CP}$ mutants were injected over a range of concentrations, and kinetic rate constants were obtained using Scrubber V2.0c software (Biologic Software, Canberra, Australia). The dissociation phase was fit well by an exponential decay model for all mutants. Using the value for $k_{-}$from the dissociation phase, the association phase was fit well by a single-site two-component binding model, yielding a value for $k_{+} . K_{\mathrm{d}}$ was calculated as the quotient of the rate constants. For the weak-binding R15A/Y79A double-mutant, fitting the association phase was not possible because the signal was too low. As part of the analysis, we considered a model including an additional step for mass transport, along with binding, which is sometimes necessary depending on the conditions and design of an SPR experiment. Adding the transport step did not improve the fit by a significant amount, so we did not use this model. 
Cell culture and lentiviral expression. Human HEK-293 cells and HT1080 cells (American Type Culture Collection, Manassas, VA) were cultured in DMEM (Life Technologies) supplemented with $10 \%$ fetal bovine serum (Sigma-Aldrich) in $5 \% \mathrm{CO}_{2}$. Cells were transfected using Transit LT1 (Mirus, Madison, WI).

Dr Wei-Lih Lee made the expression construct pEYFP-CP $\alpha 1$ by fusing mouse $\mathrm{CP} \alpha 1$ complementary DNA (GenBank U16740.1) to the C terminus of yellow fluorescent protein (YFP) in the PEYFP C-1 vector (Clontech). Site-directed mutagenesis was performed on pEGFP-CP $\beta 2$ (ref. 30) to prepare GFP-CP $\beta 2$ mutants.

To deplete endogenous $\mathrm{CP}$, we infected cells with lentivirus-expressing shRNA in pLKO.1 (ref. 46). Infected cells were selected with puromycin and used for experiments at $72 \mathrm{~h}$. The shRNA sequence was $5^{\prime}$-GCCTGGTAGAGGACATGG AAA- $3^{\prime}$, which targets all isoforms of human $\mathrm{CP} \beta$, because the isoforms are produced by alternative splicing from a single gene, and this sequence is present in the mature messenger RNA of all splice variants. The shRNA construct was developed by the RNAi Consortium at the Broad Institute ${ }^{47}$ and purchased from the Children's Discovery Institute/Genome Sequencing Center at Washington University (St Louis, MO). A non-targeting shRNA sequence recommended for the library was used as a control (Sigma-Aldrich).

For knockdown/expression experiments, cells were first infected with lentivirusexpressing shRNA targeting CP. After $72 \mathrm{~h}, 10^{6}$ infected cells were transfected with $5 \mu \mathrm{g}$ of YFP CP $\alpha 1$ and $5 \mu \mathrm{g}$ of GFP $\beta 2$ wild-type, R15A, Y79A or R15A/Y79A, then fixed and stained after an additional $24 \mathrm{~h}$. For overexpression, $10^{6}$ cells were transfected with $5 \mu \mathrm{g}$ of YFP CP $\alpha 1$ and $5 \mu \mathrm{g}$ of GFP-CP $\beta 2$ wild-type, R15A, Y79A or R15A/Y79A DNA and fixed after $48 \mathrm{~h}$. Cells were positive for both YFP and GFP, based on imaging on a Zeiss 510 laser scanning confocal microscope with a Meta detector. For localization experiments, cells were transfected with $1 \mu \mathrm{g}$ of $\mathrm{CP} \beta 2$ wildtype or R15A/Y79A and fixed and stained with the indicated antibodies after $36 \mathrm{~h}$.

Microinjection and immunofluorescence. For microinjection, HT1080 cells were injected with a solution containing $5.1 \mathrm{mg} \mathrm{ml}^{-1}$ mouse $\mathrm{CP} \alpha 1 \beta 2$ and $0.05 \mathrm{mg} \mathrm{ml}^{-1}$ fluorescent fixable dextran (Sigma-Aldrich) in injection buffer (10 mM potassium phosphate, $\mathrm{pH} 7.5,75 \mathrm{mM} \mathrm{KCl}$ ). Cells were fixed $15 \mathrm{~min}$ after injection, stained with Alexa 488-conjugated phalloidin and imaged with a $\times 63 / 1.4$ numerical aperture (NA) objective on a Zeiss 510 laser scanning confocal microscope (Zeiss, Jena, Germany). Control cells were injected with fluorescent dextran only.

For immunofluorescence, HT1080 cells were plated for $3 \mathrm{~h}$ at $37^{\circ} \mathrm{C}$ on glass coverslips previously coated with $15 \mu \mathrm{g} \mathrm{ml}^{-1}$ fibronectin (Sigma-Aldrich). Cells were fixed in $2 \%$ formaldehyde with $0.25 \%$ glutaraldehyde for $10 \mathrm{~min}$ at $37^{\circ} \mathrm{C}$ and processed as described ${ }^{33}$. Immunostaining was performed with primary and secondary antibodies listed above at concentrations of 1 and $5 \mu \mathrm{g} \mathrm{ml}^{-1}$, respectively. Cells were imaged with $\times 100 / 1.4 \mathrm{NA}$ and $\times 40 / 0.75 \mathrm{NA}$ objectives on an Olympus IX70 inverted microscope (Olympus, Melville, NY) equipped with a cooled CCD camera (CoolSnap, Photometrics, Tucson, AZ), a Zeiss Axiovert 200 (Carl Zeiss AG, Oberkochen, Germany) with a $\times 100 / 1.3$ NA objective and a Zeiss 780 (Carl Zeiss AG) with a $\times 63 / 1.5$ NA objective.

Filopodia density was quantified by counting phalloidin-stained filopodia per $10 \mu \mathrm{m}$ of cell perimeter. Fluorescence intensity in selected regions of interest was calculated using Image ${ }^{48}$ and the following formula: integrated density - (mean background fluorescence $\times$ area of the region of interest).

To quantitate fluorescence of GFP-CP at the plasma membrane, we co-expressed RFP (red fluorescent protein) as a volume marker for the cytoplasm. PM index, $((\mathrm{GFPm} / \mathrm{RFPm}) /(\mathrm{GFPc} / \mathrm{RFPc}))-1$, was calculated as described ${ }^{22}$ with the following modifications. Using ImageJ, GFPm/RFPm was calculated by dividing the GFP image by the RFP image, then measuring fluorescence intensity along a $3-\mu \mathrm{m}$-wide band drawn around the cell cortex using the freehand-line tool. GFPc and RFPc denote average cytoplasmic fluorescence intensity and was calculated using the freehand-line tool in ImageJ to define an irregularly shaped region of the cytoplasm between the membrane and nucleus. Values for PM index are near 0 for cytoplasmic proteins and $>1$ for PM proteins. The statistical significance of the membrane indices was determined using the Student's $t$-test, with a two-tailed non-paired comparison.

Co-immunoprecipitation and immunoblots. Anti-GFP was coupled to protein A Dynabeads at a concentration of $1 \mathrm{mg} \mathrm{ml}^{-1}$ (Life Technologies) according to the manufacturer's instructions. Cells were harvested $24 \mathrm{~h}$ after transfection in lysis buffer (PBS with $0.1 \%$ NP-40 and protease inhibitors aprotinin, bestatin, leupeptin, E-64, pepstatin A and phenylmethylsulphonyl fluoride). Cleared cell lysate was incubated with anti-GFP-coupled protein A Dynabeads for $3 \mathrm{~h}$ at $4{ }^{\circ} \mathrm{C}$. Beads were washed five times with PBS. Precipitated proteins were eluted by boiling in SDS and analysed by SDS-polyacrylamide gel electrophoresis and immunoblots. Blots were developed with electrochemiluminescence (ECL; PerkinElmer-Cetus, Boston, MA) and exposed to autoradiography film.

Arp2/3 complex inhibition. Cells were plated on fibronectin-coated coverslips and incubated with $100 \mu \mathrm{M}$ of CK-666, CK-869 or CK-689, or the vehicle dimethyl sulfoxide for $3 \mathrm{~h}$ at $37^{\circ} \mathrm{C}$ in $5 \% \mathrm{CO}_{2}$. For washout assays, cells were washed with growth media five times for a total of $30 \mathrm{~min}$. Cells were then fixed and stained with fluorescent phalloidin.

\section{References}

1. Pollard, T. D. \& Cooper, J. A. Actin, a central player in cell shape and movement. Science 326, 1208-1212 (2009).

2. Cooper, J. A. \& Sept, D. New insights into mechanism and regulation of actin capping protein. Int. Rev. Cell Mol. Biol. 267, 183-206 (2008).

3. Kim, T., Cooper, J. A. \& Sept, D. The interaction of capping protein with the barbed end of the actin filament. J. Mol. Biol. 404, 794-802 (2010).

4. Schafer, D. A., Jennings, P. B. \& Cooper, J. A. Dynamics of capping protein and actin assembly in vitro: uncapping barbed ends by polyphosphoinositides. $J$. Cell Biol. 135, 169-179 (1996).

5. Wear, M. A., Yamashita, A., Kim, K., Maeda, Y. \& Cooper, J. A. How capping protein binds the barbed end of the actin filament. Curr. Biol. 13, 1531-1537 (2003).

6. Edwards, M. et al. Capping protein regulators fine-tune actin assembly dynamics. Nat. Rev. Mol. Cell Biol. 15, 677-689 (2014)

7. Zhao, J. et al. CD2AP links cortactin and capping protein at the cell periphery to facilitate formation of lamellipodia. Mol. Cell. Biol. 33, 38-47 (2013).

8. Edwards, M., Liang, Y., Kim, T. \& Cooper, J. A. Physiological role of the interaction between CARMIL1 and capping protein. Mol. Biol. Cell. 24, 3047-3055 (2013).

9. Canton, D. A., Olsten, M. E., Niederstrasser, H., Cooper, J. A. \& Litchfield, D. W. The role of CKIP-1 in cell morphology depends on its interaction with actin-capping protein. J. Biol. Chem. 281, 36347-36359 (2006).

10. Isenberg, G., Aebi, U. \& Pollard, T. D. An actin-binding protein from Acanthamoeba regulates actin filament polymerization and interactions. Nature 288, 455-459 (1980).

11. Eddy, R. J., Han, J. \& Condeelis, J. S. Capping protein terminates but does not initiate chemoattractant-induced actin assembly in Dictyostelium. J. Cell Biol. 139, 1243-1253 (1997).

12. Pollard, T. D. \& Borisy, G. G. Cellular motility driven by assembly and disassembly of actin filaments. Cell 112, 453-465 (2003).

13. Dayel, M. J. et al. In silico reconstitution of actin-based symmetry breaking and motility. PLoS Biol. 7, e1000201 (2009).

14. Zhu, J. \& Mogilner, A. Mesoscopic model of actin-based propulsion. PLoS Comput. Biol. 8, e1002764 (2012).

15. Danuser, G., Allard, J. \& Mogilner, A. Mathematical modeling of eukaryotic cell migration: insights beyond experiments. Annu. Rev. Cell Dev. Biol. 29, 501-528 (2013).

16. Barkalow, K., Witke, W., Kwiatkowski, D. J. \& Hartwig, J. H. Coordinated regulation of platelet actin filament barbed ends by gelsolin and capping protein. J. Cell Biol. 134, 389-399 (1996).

17. Huang, M. et al. Cdc42-induced actin filaments are protected from capping protein. Curr. Biol. 9, 979-982 (1999).

18. Yang, C. et al. Mammalian CARMIL inhibits actin filament capping by capping protein. Dev. Cell 9, 209-221 (2005).

19. Kim, T., Ravilious, G. E., Sept, D. \& Cooper, J. A. Mechanism for CARMIL protein inhibition of heterodimeric actin-capping protein. J. Biol. Chem. 287, 15251-15262 (2012).

20. Zwolak, A., Fujiwara, I., Hammer, 3rd J. A. \& Tjandra, N. Structural basis for capping protein sequestration by myotrophin (V-1). J. Biol. Chem. 285, 25767-25781 (2010).

21. Takeda, S. et al. Two distinct mechanisms for actin capping protein regulation--steric and allosteric inhibition. PLoS Biol. 8, el000416 (2010).

22. Fujiwara, I., Remmert, K., Piszczek, G. \& Hammer, J. A. Capping protein regulatory cycle driven by CARMIL and V-1 may promote actin network assembly at protruding edges. Proc. Natl Acad. Sci. USA 111, E1970-E1979 (2014).

23. Bruck, S. et al. Identification of a novel inhibitory actin-capping protein binding motif in CD2-associated protein. J. Biol. Chem. 281, 19196-19203 (2006).

24. Hernandez-Valladares, M. et al. Structural characterization of a capping protein interaction motif defines a family of actin filament regulators. Nat. Struct. Mol. Biol. 17, 497-503 (2010).

25. Takeda, S. et al. Actin capping protein and its inhibitor CARMIL: how intrinsically disordered regions function. Phys. Biol. 8, 035005 (2011).

26. Narita, A., Takeda, S., Yamashita, A. \& Maeda, Y. Structural basis of actin filament capping at the barbed-end: a cryo-electron microscopy study. EMBO J. 25, 5626-5633 (2006).

27. Kuhn, J. R. \& Pollard, T. D. Single molecule kinetic analysis of actin filament capping. Polyphosphoinositides do not dissociate capping proteins. J. Biol. Chem. 282, 28014-28024 (2007).

28. Kim, K. et al. Structure/function analysis of the interaction of phosphatidylinositol 4,5-bisphosphate with actin-capping protein: implications for how capping protein binds the actin filament. J. Biol. Chem. 282, 5871-5879 (2007).

29. Liang, Y., Niederstrasser, H., Edwards, M., Jackson, C. E. \& Cooper, J. A Distinct roles for CARMIL isoforms in cell migration. Mol. Biol. Cell 20, 5290-5305 (2009). 
30. Schafer, D. A. et al. Visualization and molecular analysis of actin assembly in living cells. J. Cell Biol. 143, 1919-1930 (1998).

31. Park, L. et al. Cyclical action of the WASH complex: FAM21 and capping protein drive WASH recycling, not initial recruitment. Dev. Cell 24, 169-181 (2013).

32. Gorelik, R., Yang, C., Kameswaran, V., Dominguez, R. \& Svitkina, T. Mechanisms of plasma membrane targeting of formin mDia2 through its amino terminal domains. Mol. Biol. Cell 22, 189-201 (2011).

33. Mejillano, M. R. et al. Lamellipodial versus filopodial mode of the actin nanomachinery: pivotal role of the filament barbed end. Cell 118, 363-373 (2004).

34. Hug, C. et al. Capping protein levels influence actin assembly and cell motility in dictyostelium. Cell 81, 591-600 (1995).

35. Sinnar, S. A., Antoku, S., Saffin, J. M., Cooper, J. A. \& Halpain, S. Capping protein is essential for cell migration in vivo and for filopodial morphology and dynamics. Mol. Biol. Cell 25, 2152-2160 (2014).

36. Cooper, J. A., Blum, J. D. \& Pollard, T. D. Acanthamoeba castellanii capping protein: properties, mechanism of action, immunologic cross-reactivity, and localization. J. Cell Biol. 99, 217-225 (1984).

37. Loisel, T. P., Boujemaa, R., Pantaloni, D. \& Carlier, M. F. Reconstitution of actin-based motility of Listeria and Shigella using pure proteins. Nature 401, 613-616 (1999).

38. Akin, O. \& Mullins, R. D. Capping protein increases the rate of actin-based motility by promoting filament nucleation by the Arp2/3 complex. Cell 133, 841-851 (2008).

39. Hetrick, B., Han, M. S., Helgeson, L. A. \& Nolen, B. J. Small molecules CK-666 and CK-869 inhibit actin-related protein $2 / 3$ complex by blocking an activating conformational change. Chem. Biol. 20, 701-712 (2013).

40. Carlsson, A. E., Wear, M. A. \& Cooper, J. A. End versus side branching by Arp2/3 complex. Biophys. J. 86, 1074-1081 (2004).

41. Miyoshi, T. et al. Actin turnover-dependent fast dissociation of capping protein in the dendritic nucleation actin network: evidence of frequent filament severing. J. Cell Biol. 175, 947-955 (2006).

42. Zwolak, A., Uruno, T., Piszczek, G., Hammer, 3rd J. A. \& Tjandra, N. Molecular basis for barbed end uncapping by CARMIL homology domain 3 of mouse CARMIL-1. J. Biol. Chem. 285, 29014-29026 (2010).

43. Gupta, S., Maitra, R., Young, D., Gupta, A. \& Sen, S. Silencing the myotrophin gene by RNA interference leads to the regression of cardiac hypertrophy. Am. J. Physiol. Heart Circ. Physiol. 297, H627-H636 (2009).

44. Ramabhadran, V., Gurel, P. S. \& Higgs, H. N. Mutations to the formin homology 2 domain of INF2 protein have unexpected effects on actin polymerization and severing. J. Biol. Chem. 287, 34234-34245 (2012).
45. Casella, J. F., Maack, D. J. \& Lin, S. Purification and initial characterization of a protein from skeletal muscle that caps the barbed ends of actin filaments. J. Biol. Chem. 261, 10915-10921 (1986).

46. Moffat, J. et al. A lentiviral RNAi library for human and mouse genes applied to an arrayed viral high-content screen. Cell 124, 1283-1298 (2006).

47. Yang, X. et al. A public genome-scale lentiviral expression library of human ORFs. Nat. Methods 8, 659-661 (2011).

48. Schneider, C. A., Rasband, W. S. \& Eliceiri, K. W. NIH Image to ImageJ: 25 years of image analysis. Nat. Methods 9, 671-675, (2012).

\section{Acknowledgements}

We thank our lab colleagues for comments and assistance with the project and the manuscript. We thank Dr Andrey Shaw for anti-CD2AP antibodies. We thank Thomas J. Broekelmann for advice and assistance with SPR. This work was supported by NIH grant GM95509 to J.A.C. M.E. was supported by NIH training grant 5T90DA02287104. D.A.S was supported by funds from the Universitty of Virginia.

\section{Author contributions}

M.E., P.M., D.A.S. and J.A.C. designed experiments. M.E. performed all cell experiments except for microinjections. P.M. performed all biochemical experiments. D.A.S. performed the microinjection experiments. M.E., P.M., D.A.S. and J.A.C. analysed data. M.E., P.M., D.A.S. and J.A.C. wrote the paper.

\section{Additional information}

Supplementary Information accompanies this paper at http://www.nature.com/ naturecommunications

Competing financial interests: The authors declare no competing financial interests.

Reprints and permission information is available online at http://npg.nature.com/ reprintsandpermissions/

How to cite this article: Edwards, M. et al. CPI motif interaction is necessary for capping protein function in cells. Nat. Commun. 6:8415 doi: 10.1038/ncomms9415 (2015).

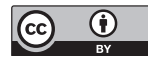

This work is licensed under a Creative Commons Attribution 4.0 International License. The images or other third party material in this article are included in the article's Creative Commons license, unless indicated otherwise in the credit line; if the material is not included under the Creative Commons license, users will need to obtain permission from the license holder to reproduce the material. To view a copy of this license, visit http://creativecommons.org/licenses/by/4.0/ 